\title{
The role of surgical intervention in primary colorectal lymphoma: A SEER population-based analysis
}

\author{
Yi-bo Cai ${ }^{1,2, *}$, Hai-yan Chen ${ }^{1,2, *}$, Jin-jie $\mathrm{He}^{1,2, *}$, Ye-ting $\mathrm{Hu}^{1,2}$, Qi Yang ${ }^{1,2}$, Liu-bo \\ Chen $^{1,2}$, Qian Xiao ${ }^{1,2}$ and Ke-feng Ding ${ }^{1,2}$ \\ ${ }^{1}$ Department of Surgical Oncology, The Second Affiliated Hospital, Zhejiang University School of Medicine, Hangzhou, \\ Zhejiang, China \\ ${ }^{2}$ Cancer Institute, Key Laboratory of Cancer Prevention and Intervention, China National Ministry of Education, Key \\ Laboratory of Molecular Biology in Medical Sciences, The Second Affiliated Hospital, Zhejiang University School of Medicine, \\ Hangzhou, Zhejiang, China \\ * These authors have contributed equally to this work \\ Correspondence to: Ke-feng Ding, email: dingkefeng@zju.edu.cn \\ Keywords: primary colorectal lymphoma; SEER; prognosis; surgical intervention; survival \\ Received: January 24, $2016 \quad$ Accepted: August 08, $2016 \quad$ Published: September 29, 2016
}

\section{ABSTRACT}

Background: Primary colorectal lymphoma ( $P C L)$ is a rare colorectal malignancy. The standard treatment and prognostic factors of PCL remain unexplored. Therefore, a large population-based study should be conducted to provide a detailed review of this disease.

Methods: We extracted the data of eligible patients with PCL registered in the SEER database from 1973 to 2011 . All statistical analyses were performed using SPSS 19.0.

Results: A total of 2050 (61.3\%) of the 3342 patients with PCL underwent surgical intervention, and 1292 (38.7\%) patients received no surgical treatment. The median overall survival was 95 months, and patients receiving surgery exhibited significantly prolonged survival (adjusted HR $=0.69, P<0.001$ ). Young age, early tumor stage, and indolent lymphoma were independent predictors of improved survival. Further survival analyses demonstrated the potential benefit of surgery in patients with early tumor stage, right-sided lesions, or diffuse large B-cell PCL. Conversely, surgical intervention did not improve the survival of patients with advanced-stage, left-sided, or indolent PCL.

Conclusion: PCL is a rare tumor that can be effectively treated. Surgical intervention may play an important role in the treatment of PCL. Early tumor stage, a right-sided lesion, and diffuse large B-cell histological PCL seem to be the clinical characteristics of optimal surgical candidates.

\section{INTRODUCTION}

Involvement of extranodal organs is a relatively common clinical finding in Non-Hodgkin lymphoma (NHL), and approximately $25-40 \%$ of patients present with primary extranodal lymphoma [1]. The majority of extranodal involvement, which accounts for 30$40 \%$, occurs in the gastrointestinal tract [2-4]. Primary colorectal lymphoma (PCL) is an uncommon original site of extranodal NHL that accounts for approximately $10-20 \%$ of gastrointestinal NHL [5-7] and comprises $0.2-0.6 \%$ of large bowel malignancies [8]. The annual incidence of colonic lymphoma has increased more than two-fold from 1.0 per 1 million in 1973 to 2.3 per 1 million in 2004 [9]. However, the diagnostic criteria of PCL are not standardized because of the rarity of PCL and lack of clinical data.

Clinical manifestations of PCL seem to be closely correlated with tumor location [10]. Abdominal pain is perceived as the most common symptom. Changes in bowel habits and bloody stools are also frequently encountered $[11,12]$. It is difficult to differentiate PCL from typical digestive diseases in adults because of these non-specific clinical symptoms. PCL is often not 
Table 1: The distribution of histologic types in PCL.

\begin{tabular}{|c|c|c|c|}
\hline \multicolumn{2}{|c|}{ ICD-O-3 Code Histologic type } & \multirow{2}{*}{ Number } & \multirow{2}{*}{$\begin{array}{c}\text { Percent } \\
4.7\end{array}$} \\
\hline 9590 & Malignant lymphoma, NOS & & \\
\hline 9591 & Malignant lymphoma, non-Hodgkin & 328 & 7.2 \\
\hline 9596 & Composite Hodgkin and non-Hodgkin lymphoma & 1 & 0.0 \\
\hline 9650 & Hodgkin lymphoma, NOS & 18 & 0.4 \\
\hline 9652 & Hodgkin lymphoma, mixed cellularity, NOS & 9 & 0.2 \\
\hline 9653 & Hodgkin lymphoma, lymphocytic deplet., NOS & 3 & 0.1 \\
\hline 9659 & Hodgkin lymph., nodular lymphocyte predom. & 1 & 0.0 \\
\hline 9663 & Hodgkin lymphoma, nodular sclerosis, NOS & 1 & 0.0 \\
\hline 9670 & ML, small B lymphocytic, NOS & 118 & 2.6 \\
\hline 9671 & ML, lymphoplasmacytic & 21 & 0.5 \\
\hline 9673 & Mantle cell lymphoma & 329 & 7.3 \\
\hline 9675 & ML, mixed sm. and lg. cell, diffuse & 41 & 0.9 \\
\hline 9680 & ML, large B-cell, diffuse & 1886 & 41.7 \\
\hline 9684 & ML, large B-cell, diffuse, immunoblastic, NOS & 182 & 4.0 \\
\hline 9687 & Burkitt lymphoma, NOS & 243 & 5.4 \\
\hline 9690 & Follicular lymphoma, NOS & 120 & 2.6 \\
\hline 9691 & Follicular lymphoma, grade 2 & 67 & 1.5 \\
\hline 9695 & Follicular lymphoma, grade 1 & 125 & 2.8 \\
\hline 9698 & Follicular lymphoma, grade 3 & 42 & 0.9 \\
\hline 9699 & Marginal zone B-cell lymphoma, NOS & 639 & 14.1 \\
\hline 9702 & Mature T-cell lymphoma, NOS & 37 & 0.8 \\
\hline 9714 & Anaplastic large cell lymphoma, T-cell and Null cell type & 27 & 0.6 \\
\hline 9717 & Intestinal T-cell lymphoma & 8 & 0.2 \\
\hline 9719 & NK/T-cell lymphoma, nasal and nasal-type & 4 & 0.1 \\
\hline 9724 & $\begin{array}{l}\text { SystemicEBV pos. T-cell lymphoproliferative } \\
\text { disease of childhood }\end{array}$ & 1 & 0.0 \\
\hline 9727 & Precursor cell lymphoblastic lymphoma, NOS & 3 & 0.1 \\
\hline 9731 & Plasmacytoma, NOS & 19 & 0.4 \\
\hline 9734 & Plasmacytoma, extramedullary & 36 & 0.8 \\
\hline 9735 & Plasmablastic lymphoma & 11 & 0.2 \\
\hline \multicolumn{2}{|c|}{ Total patients with PCL listed in SEER (1973-2011) } & 4525 & 100.0 \\
\hline \multicolumn{2}{|c|}{ Patients selected for analysis ${ }^{\text {a }}$} & 3451 & 76.3 \\
\hline
\end{tabular}

Abbreviation: PCL, Primary Colorectal Lymphoma; ICD-O-3, International Classification of Diseases for Oncology, 3rd Edition; NOS, Not Otherwise Specified; ML, Malignant lymphoma; SEER, Surveillance, Epidemiology, and End Results.

a ICD-O-3 Histological Type Codes of selected patients in this analysis are 9673, 9680, 9687, 9690, 9691, 9695, 9698, and 9699, which are marked in bold.

discovered until serious complications arise, such as perforation or obstruction [10]. Cai et al. [13] reported that more than half of the patients with PCL underwent emergency surgeries for serious complications. Therefore, surgeons should remain vigilant about the diagnostic possibility of PCL in emergent patients. Inflammatory bowel disease and immunosuppression are considered potential risk factors of PCL $[14,15]$. The optimal therapeutic approach for the treatment of PCL remains controversial because PCL is rarely encountered in clinical practice, and few random controlled trials have been performed. Historically, patients with PCL were managed using a multidisciplinary approach with surgery, chemotherapy and radiotherapy in selected patients $[13,15,16]$. However, there is no enough evidence to support a correlation of surgical intervention with better 


\begin{tabular}{|c|c|c|c|c|}
\hline Variable & All Patients & Surgery & No Surgery & $P$ Value \\
\hline Total Patients (\%) & $3342(100 \%)$ & $2050(61.3 \%)$ & $1292(38.7 \%)$ & \\
\hline Age (SD) & $63.9 \pm 18.3$ & $63.4 \pm 18.9$ & $64.5 \pm 17.2$ & $0.501^{\mathrm{a}}$ \\
\hline Gender (\%) & & & & $0.772^{b}$ \\
\hline Male & $2046(61.2 \%)$ & $1259(61.4 \%)$ & $787(60.9 \%)$ & \\
\hline Female & $1296(38.8 \%)$ & $791(38.6 \%)$ & $505(39.1 \%)$ & \\
\hline Race (\%) & & & & $0.370^{\mathrm{b}}$ \\
\hline White & $2275(83.0 \%)$ & 1714(83.6\%) & 1061(82.1\%) & \\
\hline Black & $189(5.7 \%)$ & $108(5.3 \%)$ & $81(6.3 \%)$ & \\
\hline Asian & $320(9.6 \%)$ & $197(9.6 \%)$ & $123(9.5 \%)$ & \\
\hline Others & $58(1.7 \%)$ & $31(1.5 \%)$ & $27(2.1 \%)$ & \\
\hline Stage $(\%)$ & & & & $<0.001^{\mathrm{b}}$ \\
\hline Stage IE & $1396(41.8 \%)$ & $826(40.3 \%)$ & $570(44.1 \%)$ & $0.029^{\mathrm{b}}$ \\
\hline Stage IIE & $767(23.0 \%)$ & $597(29.1 \%)$ & $170(13.2 \%)$ & $<0.001^{\mathrm{b}}$ \\
\hline Stage IIIE & $168(5.0 \%)$ & $88(4.3 \%)$ & $80(6.2 \%)$ & $0.014^{\mathrm{b}}$ \\
\hline Stage IVE & $712(21.3 \%)$ & $379(18.5 \%)$ & $333(25.8 \%)$ & $<0.001^{\mathrm{b}}$ \\
\hline Not applicable & $114(3.4 \%)$ & $109(5.3 \%)$ & $5(0.4 \%)$ & $<0.001^{\mathrm{b}}$ \\
\hline Unknown & $185(5.5 \%)$ & $51(2.5 \%)$ & $134(10.4 \%)$ & $<0.001^{\mathrm{b}}$ \\
\hline Radiation (\%) & & & & $<0.001^{\mathrm{b}}$ \\
\hline Yes & $295(8.8 \%)$ & $143(7.0 \%)$ & $152(11.8 \%)$ & $<0.001^{\mathrm{b}}$ \\
\hline No & $3025(90.5 \%)$ & 1890(92.2\%) & $1135(87.8 \%)$ & $<0.001^{\mathrm{b}}$ \\
\hline Unknown & $22(0.7 \%)$ & $17(0.8 \%)$ & $5(0.4 \%)$ & \\
\hline Location (\%) & & & & $<0.001^{\mathrm{b}}$ \\
\hline Cecum & $1165(34.9 \%)$ & $797(38.9 \%)$ & $368(28.5 \%)$ & $<0.001^{\mathrm{b}}$ \\
\hline Appendix & $109(3.3 \%)$ & $91(4.4 \%)$ & $18(1.4 \%)$ & $<0.001^{\mathrm{b}}$ \\
\hline Right colon & $386(11.5 \%)$ & $247(12.0 \%)$ & $139(10.7 \%)$ & \\
\hline Hepatic flexure & $65(1.9 \%)$ & $43(1.9 \%)$ & $22(1.7 \%)$ & \\
\hline Transverse colon & $165(4.9 \%)$ & $103(5.0 \%)$ & $62(4.8 \%)$ & \\
\hline Splenic flexure & $41(1.2 \%)$ & $32(1.6 \%)$ & $9(0.7 \%)$ & $0.027^{\mathrm{b}}$ \\
\hline Left colon & $91(2.7 \%)$ & $58(2.8 \%)$ & $33(2.6 \%)$ & \\
\hline Sigmoid colon & $320(9.6 \%)$ & $188(8.9 \%)$ & $132(10.2 \%)$ & \\
\hline Overlappping lesion & $100(3.0 \%)$ & $62(3.0 \%)$ & $38(2.9 \%)$ & \\
\hline Colon, NOS & $358(10.7 \%)$ & $166(8.1 \%)$ & $192(14.9 \%)$ & $<0.001^{\mathrm{b}}$ \\
\hline Rectosigmoid & $96(2.9 \%)$ & $47(2.3 \%)$ & $49(3.8 \%)$ & $0.011^{\mathrm{b}}$ \\
\hline Rectum & $446(13.3 \%)$ & $216(10.5 \%)$ & $230(17.8 \%)$ & $<0.001^{\mathrm{b}}$ \\
\hline Histology (\%) & & & & $<0.001^{\mathrm{b}}$ \\
\hline NHL, large B-cell & $1828(54.7 \%)$ & $1186(57.9 \%)$ & $642(49.7 \%)$ & $<0.001^{\text {b }}$ \\
\hline Marginal zone B-cell & $618(18.5 \%)$ & $358(17.5 \%)$ & $265(20.5 \%)$ & $0.028^{\mathrm{b}}$ \\
\hline Burkitt lymphoma & $233(7.0 \%)$ & $154(7.5 \%)$ & $79(6.1 \%)$ & \\
\hline Follicular lymphoma & $346(10.4 \%)$ & $200(9.8 \%)$ & $146(11.3 \%)$ & \\
\hline Mantle cell lymphoma & $317(9.5 \%)$ & $157(7.7 \%)$ & $160(13.4 \%)$ & $<0.001^{b}$ \\
\hline
\end{tabular}




\begin{tabular}{|l|l|l|l|l|}
\hline Year of diagnosis (\%) & & & $<0.001^{\text {b }}$ \\
\hline $1973-1990$ & $274(8.2 \%)$ & $257(12.5 \%)$ & $17(1.3 \%)$ & $<0.001^{\text {b }}$ \\
\hline $1991-2000$ & $753(22.5 \%)$ & $478(23.3 \%)$ & $275(21.3 \%)$ & \\
\hline $2001-2005$ & $991(29.7 \%)$ & $580(28.3 \%)$ & $411(31.8 \%)$ & $0.030^{\text {b }}$ \\
\hline $2006-2011$ & $1324(39.6 \%)$ & $735(35.8 \%)$ & $589(45.6 \%)$ & $<0.001^{\text {b }}$ \\
\hline $\begin{array}{l}\text { Abbreviation: PCL, Primary Colorectal Lymphoma; SD, Standard Deviation; NOS, Not Otherwise Specified; } \\
\text { NHL, Non-Hodgkin's Lymphoma. } \\
\text { a Wilcoxon rank sum test. } \\
\text { b Pearson Chi-square test. }\end{array}$ & & \\
\hline
\end{tabular}

long-term survival, and the relevant factors affecting surgical clinical efficacy in the treatment of PCL remain unexplored. Information on the epidemiology, surgical treatment and prognosis of PCL is limited because of the rarity of this disease. Therefore, the main purpose of this retrospective study based on the authoritative Surveillance, Epidemiology, and End Results (SEER) database is to provide the best available information to improve clinicians' understanding of PCL. This study also revealed the potential predictive factors of surgical outcomes and evaluated the role of surgery to a certain degree.

\section{RESULTS}

\section{Patient demographics and tumor characteristics}

A total of 4525 patients with PCL were identified in the SEER database from 1973 to 2011. Considering the heterogeneous nature of lymphoma, we focused on the five most common histological subtypes (Table 1), which accounted for $76.3 \%$ of all patients with PCL in the SEER database. Of the candidate patients, 3342 cases met the inclusion criteria (Figure 1), including 2050 cases $(61.3 \%)$ with surgical intervention and 1292 cases $(38.7 \%)$ without surgical intervention. The demographics, tumor characteristics, and treatment in formation for these two groups were summarized in Table 2. The mean age of patients at PCL diagnosis was 63.9 years old $(\mathrm{SD}=18.3$ years old). Male patients comprised a larger proportion $(N=2046,61.2 \%)$, and most patients were white $(N=$ $2275,83.0 \%$ ). Approximately $41.8 \%$ of PCL patients were categorized as stage IE ( $N=1396), 23 \%$ as stage IIE $(N=767), 5 \%$ as stage IIIE $(N=168)$, and $21.3 \%$ as stage IVE $(N=712)$. Most patients who underwent surgical intervention were diagnosed at stage IIE $(P<$ $0.001)$, whereas fewer patients were in stage IVE $(P<$ $0.001)$. A total of 1165 cases $(34.9 \%)$ originated from the cecum, which comprised the largest proportion. The two most common lymphoma types were diffuse large B-cell $(N=1828,54.7 \%)$ and marginal zone B-cell $(N=$ $618,18.5 \%)$. Approximately $56.6 \%$ of PCL patients ( $N=$ $1890)$ underwent surgical intervention. The rate of surgery presented a descending trend from $94.2 \%(257 / 274)$ in the period 1973-1990 to 54.9\% (735/1324) in the period 20062011. Radiotherapy was only performed in $4.5 \%(N=152)$ of patients with PCL.

\section{Survival and prognostic factors}

Approximately 2198 cases (65.8\%) with complete survival information were eligible for inclusion in accurate analyses of the overall survival (OS) of patients with PCL (Figure 1). The eligible study population was not significantly different from the total population (Table S1). The median OS was 95 months (range $=79.5-110.5$ months) (Table 3). Younger patients exhibited improved prognosis compared to elderly patients (age $\leq 50$ years versus $>70$ years, $P<0.001)$. Non-white patients exhibited prolonged survival $(P=0.027)$. Tumor stage was a crucial predictor of survival in PCL patients. Advanced tumor stage correlated with decreased survival $(P<$ 0.001). Patients undergoing surgical intervention showed improved survival (113 months versus 74 months, $P=$ 0.006) (Figure 2). Marginal zone B-cell and follicular histological types $(P<0.001)$, as well as year of diagnosis $>2000(P<0.001)$, were potential predictors of better prognosis. Adjusted Cox regression analyses revealed that advanced stage and tumor localization in the leftsided colon were independent factors of poor prognosis (Table 3). Younger age, surgical intervention (adjusted hazard ratio $(\mathrm{HR})=0.69,95 \%$ confidence intervals $(\mathrm{CI})$ : 0.59-0.81, $P<0.001$ ), marginal zone B-cell lymphoma, follicular lymphoma, and year of diagnosis $>2000$ were independent predictors of improved outcomes. The local excision (LE) group $(N=617,29.4 \%)$ was positively associated with survival [144 months versus 102 months for the LE and radical excision (RE) groups, respectively, $P<0.001$ ] (Table S2). However, this survival difference was not confirmed in multivariate analysis (adjusted HR $=1.01,95 \%$ CI: $0.83-1.21)$. Further analysis revealed that the number of patients with survival times shorter than 3 months in the LE group was lower than in the RE and no-surgery groups $(P=0.010)$. Most patients with stage IE PCL underwent LE (54.7\%), while stage IVE PCL was the most common stage in patients without surgery $(P<$ $0.001)$. 


\section{Patients diagnosed as Primary colorectal}

lymphoma (PCL) (ICD-O-3 primary site codes:

C180-189,C199,C209; ICD-O-3 histology codes:

$9673,9680,9687,9690-9680,9699)$ based

upon SEER registries in 1973-2011.

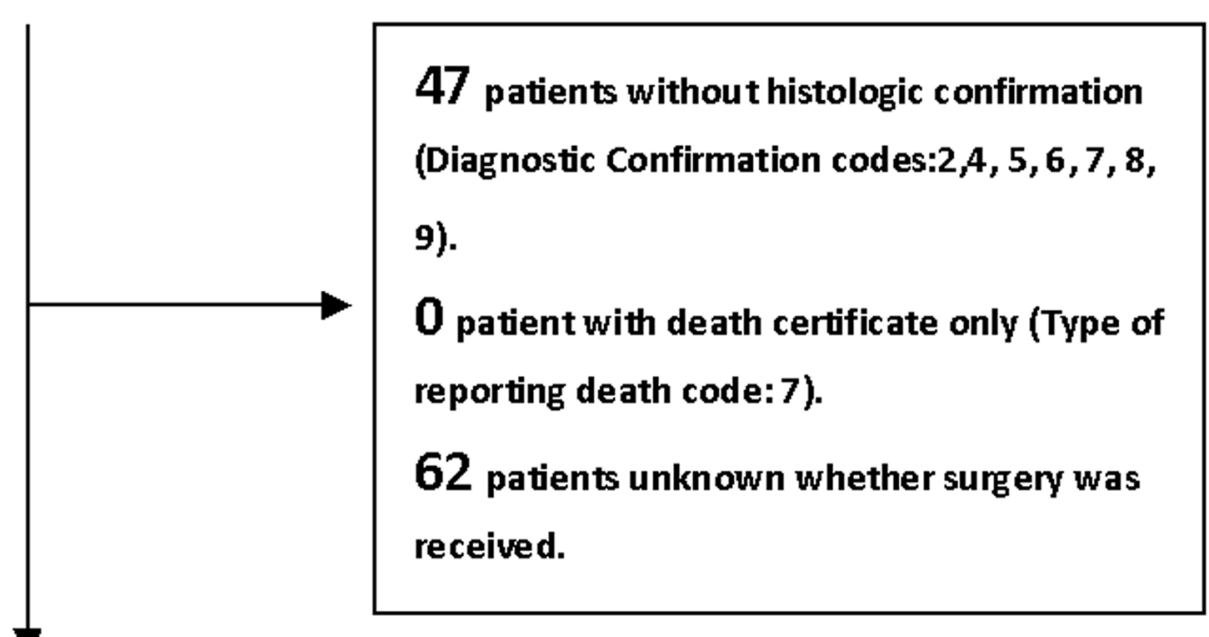

3342 patients meet the inclusion criteria to describe patient characteristics.

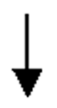

2198 patients with one primary only (Sequence number code: 0 ), active fellow-up (Type of fellow-up expected code: 2 ) and explicit survival results (SEER cause-specific death code: 0,1 and SEER other cause of death code: 0,1$)$ meet the inclusion criteria in survival study.

Figure 1: Flow diagram of patient inclusion and exclusion. 3342 patients with primary colorectal lymphoma were identified based upon SEER database from 1973 to 2011, and 2198 of them were further extracted for survival analysis. 
Table 3: Univariate and Multivariate Analyses for Overall Survival.

\begin{tabular}{|c|c|c|c|c|c|c|}
\hline \multirow[b]{2}{*}{ Variable } & \multicolumn{2}{|l|}{ Univariate } & \multicolumn{2}{|c|}{ Unadjusted model } & \multicolumn{2}{|c|}{ Adjusted model } \\
\hline & $\begin{array}{l}\text { Median survival] } \\
\text { (95\%CI, months) }\end{array}$ & P value ${ }^{a}$ & HR & Pvalue $^{b}$ & HR & P value ${ }^{b}$ \\
\hline Overall & $95(79.5-110.5)$ & & & & & \\
\hline \multicolumn{7}{|l|}{ Age } \\
\hline$\leq 50$ & $221^{\mathrm{c}}$ & & $0.46(0.38-0.57)$ & $<0.001$ & $0.46(0.38-0.56)$ & $<0.001$ \\
\hline $51-70$ & $152(116.1-187.9)$ & & $0.54(0.46-0.64)$ & $<0.001$ & $0.56(0.48-0.66)$ & $<0.001$ \\
\hline$>70$ & $53(43.6-62.4)$ & $<0.001$ & 1 & & 1 & \\
\hline \multicolumn{7}{|l|}{ Gender } \\
\hline Male & $103(82.7-123.3)$ & & NA & & NA & \\
\hline Female & $92(70.3-113.7)$ & 0.527 & & & & \\
\hline \multicolumn{7}{|l|}{ Race } \\
\hline White & $91(75.6-106.4)$ & & 1 & & NA & \\
\hline Nonwhite & $171(124.6-217.4)$ & 0.027 & $0.95(0.78-1.16)$ & 0.615 & & \\
\hline \multicolumn{7}{|l|}{ Stage } \\
\hline Stage IE & $158(127.3-188.7)$ & & 1 & & 1 & \\
\hline Stage IIE & $92(60.6-123.4)$ & & $1.35(1.12-1.62)$ & 0.002 & $1.34(1.12-1.61)$ & 0.001 \\
\hline Stage IIIE & $65(33.7-96.3)$ & & $1.69(1.24-2.30)$ & $<0.001$ & $1.64(1.21-2.23)$ & 0.002 \\
\hline Stage IVE & $35(18.7-51.3)$ & $<0.001$ & $2.13(1.79-2.53)$ & $<0.001$ & $2.13(1.79-2.52)$ & $<0.001$ \\
\hline \multicolumn{7}{|l|}{ Radiation } \\
\hline No & $99(82.0-116.0)$ & & NA & & NA & \\
\hline Yes & $88(62.1-113.9)$ & 0.930 & & & & \\
\hline \multicolumn{7}{|l|}{ Surgery } \\
\hline No & $74(59.8-88.2)$ & & 1 & & 1 & \\
\hline Yes & $113(91.1-134.9)$ & 0.006 & $0.69(0.59-0.81)$ & $<0.001$ & $0.69(0.59-0.81)$ & $<0.001$ \\
\hline \multicolumn{7}{|l|}{ Location } \\
\hline Right-sided colon & $99(79.2-118.8)$ & & $1.16(0.94-1.43)$ & 0.173 & $1.15(0.94-1.42)$ & 0.180 \\
\hline Left-sided colon & $80(53.2-106.8)$ & & $1.39(1.09-1.78)$ & 0.008 & $1.37(1.07-1.74)$ & 0.012 \\
\hline Rectum & $121(73.3-168.7)$ & 0.075 & 1 & & 1 & \\
\hline \multicolumn{7}{|l|}{ Histology } \\
\hline NHL, large B-cell & $73(59.5-86.5)$ & & 1 & & 1 & \\
\hline Marginal zone B-cell & $170^{\mathrm{c}}$ & & $0.63(0.50-0.80)$ & $<0.001$ & $0.62(0.49-0.78)$ & $<0.001$ \\
\hline Burkitt lymphoma & $221^{\mathrm{c}}$ & & $0.98(0.74-1.31)$ & 0.904 & $1.00(0.75-1.33)$ & 0.997 \\
\hline Follicular lymphoma & $166(112.3-219.7)$ & & $0.66(0.50-0.88)$ & 0.004 & $0.66(0.50-0.87)$ & 0.003 \\
\hline Mantle cell lymphoma & $70(37.5-102.5)$ & $<0.001$ & $0.87(0.66-1.14)$ & 0.317 & $0.86(0.66-1.13)$ & 0.279 \\
\hline \multicolumn{7}{|l|}{ Year of diagnosis } \\
\hline $1973-1990$ & $38(15.3-50.7)$ & & 1 & & 1 & \\
\hline $1991-2000$ & $50(32.9-67.1)$ & & $0.87(0.68-1.11)$ & 0.268 & $0.88(0.69-1.12)$ & 0.312 \\
\hline $2001-2005$ & $138^{\mathrm{c}}$ & & $0.52(0.40-0.68)$ & $<0.001$ & $0.53(0.41-0.69)$ & $<0.001$ \\
\hline $2006-2011$ & $153(107.7-198.3)$ & $<0.001$ & $0.53(0.41-0.69)$ & $<0.001$ & $0.54(0.41-0.69)$ & $<0.001$ \\
\hline \multicolumn{6}{|c|}{ Harrell concordance index ${ }^{d}$} & 0.681 \\
\hline
\end{tabular}


Table 4: Analysis of Effects of Surgical Treatment on Overall Survival

\begin{tabular}{|c|c|c|c|c|c|c|c|}
\hline \multirow[b]{2}{*}{ Variable } & \multicolumn{2}{|c|}{ Surgery } & \multicolumn{2}{|c|}{ No Surgery } & \multirow[b]{2}{*}{$P^{a}$} & \multirow[b]{2}{*}{ Hazard ratio } & \multirow[b]{2}{*}{$\mathbf{P}^{b}$} \\
\hline & Number(\%) & $\begin{array}{c}\text { 10-year } \\
\text { OS }\end{array}$ & Number(\%) & $\begin{array}{l}\text { 10-yea } \\
\text { r } \\
\text { OS }\end{array}$ & & & \\
\hline Overall & $1360(61.9)$ & 0.495 & $838(38.1)$ & 0.422 & 0.006 & $0.69(0.59-0.81)$ & $<0.001$ \\
\hline \multicolumn{8}{|l|}{ Age } \\
\hline$\leq 50$ & $342(63.9)$ & 0.649 & 193(36.1) & 0.473 & 0.001 & $0.66(0.47-0.93)$ & 0.018 \\
\hline $51-70$ & $508(60.7)$ & 0.552 & $329(39.3)$ & 0.503 & 0,122 & $0.68(0.51-0.91)$ & 0.010 \\
\hline$>70$ & $510(61.7)$ & 0.317 & $316(38.3)$ & 0.300 & 0.951 & $0.74(0.59-0.94)$ & 0.011 \\
\hline \multicolumn{8}{|l|}{ Stage } \\
\hline Stage I E & $531(58.9)$ & 0.599 & $371(41.1)$ & 0.473 & $<0.001$ & $0.57(0.44-0.73)$ & $<0.001$ \\
\hline Stage II E & $405(80.2)$ & 0.493 & $100(19.8)$ & 0.399 & 0.137 & $0.71(0.50-1.01)$ & 0.058 \\
\hline Stage III E & $62(52.1)$ & 0.518 & $57(47.9)$ & 0.353 & 0.138 & $0.80(0.43-1.50)$ & 0.485 \\
\hline Stage IV E & $258(53.4)$ & 0.359 & $225(46.6)$ & 0.353 & 0.557 & $0.89(0.67-1.17)$ & 0.400 \\
\hline \multicolumn{8}{|l|}{ Location } \\
\hline Right-side colon & $870(68.4)$ & 0.501 & $402(31.6)$ & 0.405 & 0.002 & $0.68(0.53-0.80)$ & $<0.001$ \\
\hline Left-side colon & $214(61.3)$ & 0.432 & $135(38.7)$ & 0.434 & 0.629 & $0.79(0.56-1.13)$ & 0.197 \\
\hline Rectum & $176(49.4)$ & 0.544 & $180(50.6)$ & 0.474 & 0.156 & $0.82(0.55-1.22)$ & 0.336 \\
\hline \multicolumn{8}{|l|}{\begin{tabular}{|l|l} 
Histology & \\
\end{tabular}} \\
\hline NHL, large B-cell & $787(64.8)$ & 0.434 & $428(35.2)$ & 0.381 & 0.019 & $0.65(0.54-0.82)$ & $<0.001$ \\
\hline \multicolumn{2}{|c|}{ Marginal zone B-cell 216(57.9) } & 0.624 & $157(42.1)$ & 0.463 & 0.109 & $0.86(0.55-1.36)$ & 0.523 \\
\hline \multicolumn{2}{|c|}{ Burkitt lymphoma $\quad 130(67.7)$} & 0.652 & $62(22.3)$ & 0.438 & 0.031 & $0.86(0.48-1.53)$ & 0.599 \\
\hline \multicolumn{2}{|c|}{ Follicular lymphoma $128(58.7)$} & 0.562 & $90(41.3)$ & 0.590 & 0.959 & $0.72(0.39-1.32)$ & 0.288 \\
\hline \multicolumn{2}{|c|}{ Mantle cell lymphoma 99(49.5) } & 0.454 & $101(50.5)$ & 0.375 & 0.573 & $0.95(0.56-1.61)$ & 0.843 \\
\hline \multicolumn{8}{|c|}{ Year of diagnosis } \\
\hline \begin{tabular}{l|l}
$1973-1990$ & \\
\end{tabular} & $194(95.1)$ & 0.340 & $10(4.9)$ & 0.000 & 0.033 & $1.41(0.49-4.08)$ & 0.529 \\
\hline $1991-2000$ & $305(62.8)$ & 0.402 & $181(37.2)$ & 0.300 & 0.031 & $0.69(0.52-0.92)$ & 0.011 \\
\hline $2001-2005$ & $372(58.4)$ & 0.609 & $265(41.6)$ & 0.479 & 0.008 & $0.73(0.54-0.98)$ & 0.034 \\
\hline 2006-2011 & $489(56.1)$ & 0.575 & $382(43.9)$ & 0.467 & 0.015 & $0.70(0.54-0.92)$ & 0.009 \\
\hline
\end{tabular}

Abbreviation: CI, Confidence Interval; OS, Overall Survival; NHL, Non-Hodgkin's Lymphoma

a 10-year overall survival rate was determined by the Kaplan-Meier method. $P$ value was calculated by the Log Rank test. b Hazard ratio and $\mathrm{P}$ value was calculated by Cox proportional hazards model.

\section{Correlated factors associated with the effects of surgical intervention}

A subgroup analysis of survival was performed to determine the factors that correlated with the effect of surgical intervention, and the results are displayed in Table 4. Age had no effect on surgical efficacy in PCL. Patients in the stage IE PCL (adjusted HR $=0.57,95 \%$ CI: 0.44-0.73) subgroup who underwent surgery exhibited an improved survival rate by several years, but this survival benefit from surgery was lost in stages IIE-IVE PCL. The surgery group showed improved survival in patients with tumors localized in the right-sided colon (adjusted HR $=0.68,95 \% \mathrm{CI}: 0.53-0.80)$ compared to the no-surgery group. The correlation between surgery and histological type was complicated. The survival benefit of surgery was only observed in the diffuse large B-cell PCL subtype (adjusted $\mathrm{HR}=0.65,95 \% \mathrm{CI}: 0.54-0.82$ ). These results are illustrated in the Kaplan-Meier survival curves in Figure 3. No significant survival improvement was found in the remaining cohorts (left-sided colon, rectum, marginal zone B-cell lymphoma, follicular lymphoma, Burkitt lymphoma, and mantle cell lymphoma) with surgical intervention. 


\section{DISCUSSION}

PCL is a rare colorectal neoplasm with a gradually increasing incidence $[9,11,17]$. Previous studies that investigated the epidemiological features and survival of PCL were predominantly based on populations from a single institution and case reports; these studies only involved 7-95 patients [8, 10-13,16, 18-26]. We identified 3342 patients with PCL in the SEER database to identify potential prognostic factors and the role of surgical intervention in PCL management. To our knowledge, this study is the largest population-based study to investigate factors associated with surgical efficacy for this relatively rare tumor.

Our results demonstrated that patients were diagnosed at the mean age of 63.9 years with a male predominance (male: female $=1.58: 1$ ), which is similar to previous studies in the West and East $[10,12,18,26]$. Approximately $41.8 \%$ and $21.3 \%$ of PCL patients were in Ann Arbor stages IE and IVE, respectively, which is similar to the results from a German multicenter trial [27]. Consistent with published reports $[8,10,11,16,20]$, the most frequent tumor location was the cecum (34.9\%), which primarily results from the abundance of lymphoid tissues in the lesion. The most common histological subtype in the present study was diffuse large B-cell $(41.6 \%)$, and the proportion of T-cell lineage from the present results was lower than $17.9 \%$, which was reported previously by the Korean Association for the Study of Intestinal Diseases [12]. Racial differences may partially explain this lack of conformity.

Age at diagnosis was an important predictor of survival, and younger patients (age $\leq 50$ years) exhibited improved survival outcomes. This finding was corroborated by evidence from Droletet al. [11]. Early tumor stage and indolent lymphoma, which are good prognostic factors of survival in primary gastrointestinal lymphoma[7], were also associated with improved survival in PCL. This association between aggressive biological behavior and reduced survival was previously observed by Fan et al. [8], who demonstrated that patients with intermediate- or low- histological grade cancer showed prolonged survival compared to patients with high-grade cancer (132.0 months versus 62.2 months, $\mathrm{P}$ $=0.05)$. An increasing survival trend was observed over time, which may be due to improvements in diagnostic techniques and a multimodality approach to treatment. In particular, the rapidly developing targeted therapy for CD20-positive B lymphoma has further improved survival in lymphoma patients [28, 29].

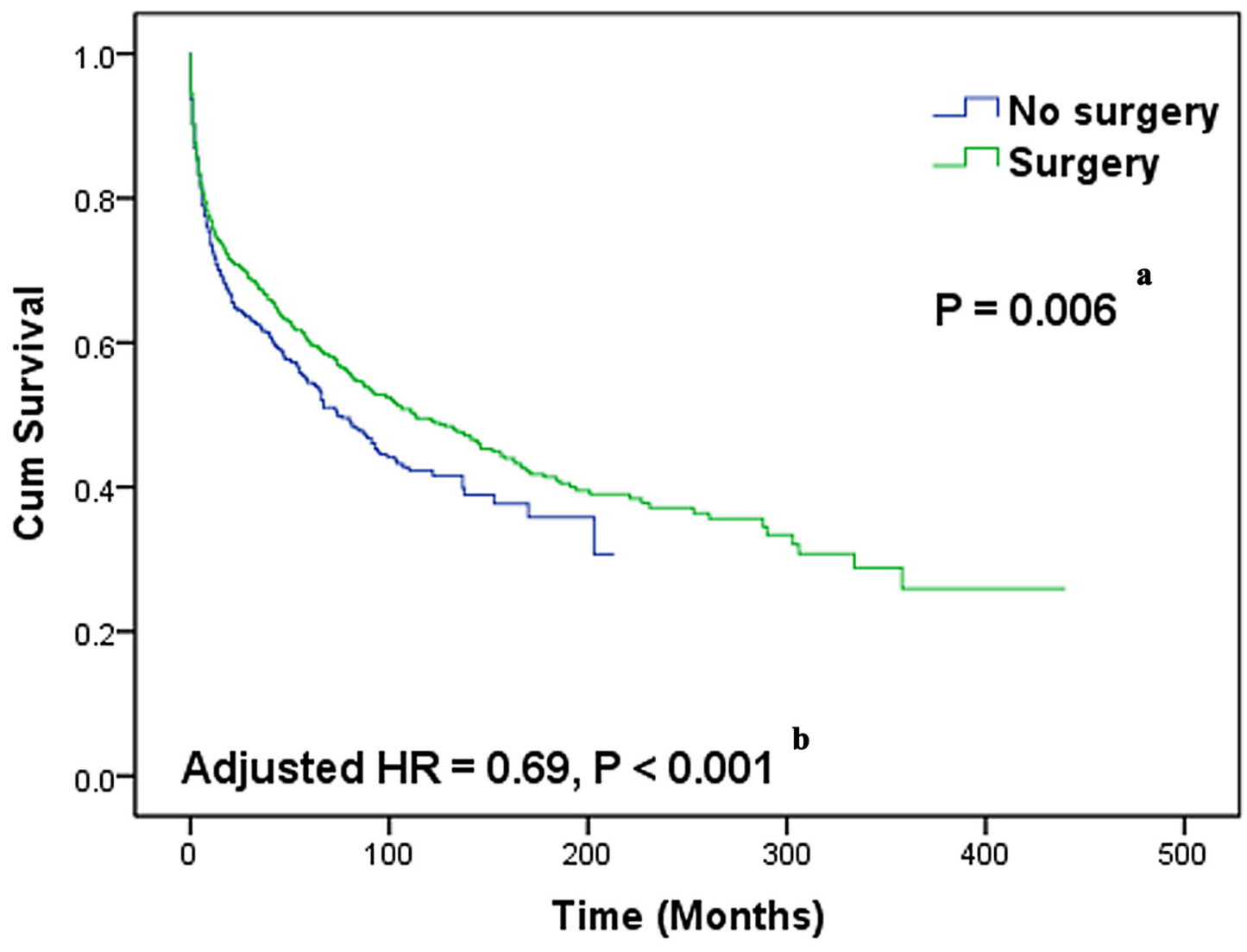

Figure 2: Kaplan-Meier curves of overall survival differences between patients with and without surgical intervention. Patients undergoing surgical intervention could have prolonged survival. ${ }^{\text {a }}$ Log-rank test was performed in univariate analysis to detect survival differences. ${ }^{b}$ The Cox multivariate proportional hazard model was used to estimate adjusted hazard ratios (HRs). 
Current PCL treatment has evolved into a combined therapy that involves surgery, chemotherapy, and radiotherapy $[10,13,16,23]$. However, the role of surgery in this comprehensive PCL therapy strategy is still subject to debate. Most authors suggest surgery as the optimal initial treatment, regardless of clinical stage, because they believe that surgery provides important prognostic information, prevents complications, and provides the possibility of cure with or without adjuvant therapy [8,
11, 16, 24, 26]. Nevertheless, other investigators argue that NHL is a systemic disease and that surgical cure is unsuitable for advanced gastrointestinal lymphoma. Koniaris et al. [30] and Cai et al. [13] recommend systemic chemotherapy as the standard treatment for PCL and suggest that surgery should be reserved for PCL with serious complications, such as hemorrhage, obstruction and perforation. Nonetheless, because that the details of chemotherapy are unavailable from the SEER
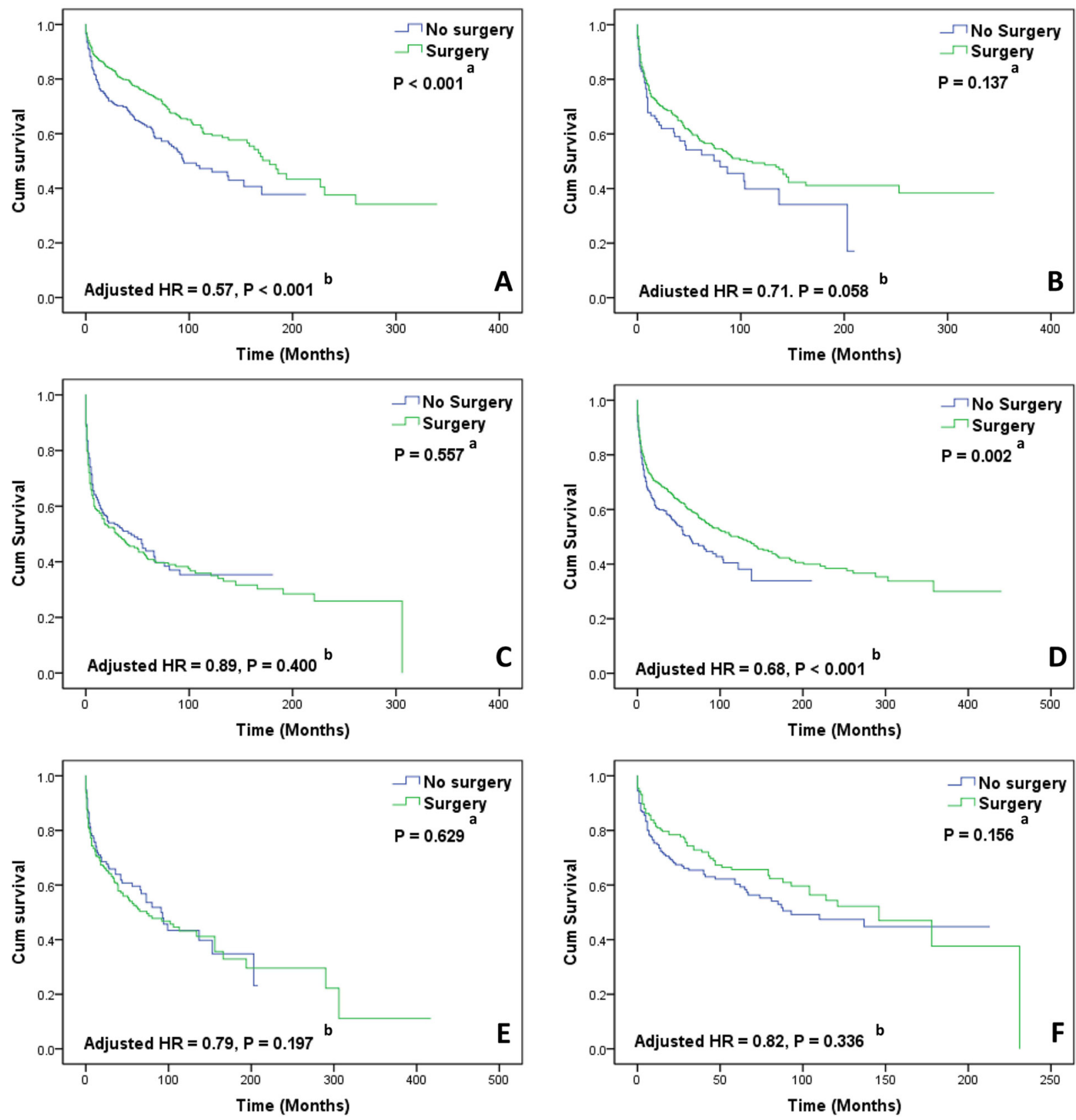

Figure 3: Kaplan-Meier curves of overall survival in subgroup analyses. A. Patients with stage IE tumor, D. Patients with rightsided colonic lymphoma could benefit from surgical intervention and B. Patients with stage IIE tumor, C. Patients with stage IVE tumor, E. Patients with left-sided colonic lymphoma, F. Patients with rectal lymphoma did not achieve survival benefit from surgical intervention. ${ }^{a}$ Log-rank test was performed in univariate analysis to detect survival differences. ${ }^{\mathrm{b}}$ The Cox multivariate proportional hazard model was used to estimate adjusted hazard ratios (HRs). 
database, we are incapable to evaluate the actual role of chemotherapy in the treatment of PCL. The present results demonstrated that patients who received surgical intervention exhibited significant survival improvement (113 months versus 74 months, adjusted HR $=0.69,95 \%$ CI: 0.59-0.81) and were consistent with previous study [26], supporting the potential important role of surgery in the comprehensive therapy of PCL.

Patients receiving surgical intervention should be assessed and selected according to their clinical and tumor features. A survival benefit from surgery was noted in patients with stage IE PCL in the present study, but this benefit was lost in patients with advanced tumor stage, which is consistent with the results reported in gastric lymphoma [31]. This finding was also corroborated by evidence from Cai et al. [13], who demonstrated that all patients with stage IVE PCL had disease progression after emergency surgery. Therefore, some oncologists recommend that patients with aggressive tumors in stages IIIE-IVE should be referred to clinical trials rather than undergoing surgery or chemotherapy $[10,15]$.

The location of extranodal NHL seems to be associated with surgical efficacy. Surgical intervention in colorectal lymphoma exerted a significant positive effect on survival outcomes of right-sided [right-sided colonic (adjusted HR $=0.68, P<0.001$ )] PCL but lost efficacy in left-sided [left-sided colonic (adjusted HR $=0.79, P=0.197$ ) or rectal (adjusted HR $=0.82, P$ $P=0.336)]$ PCL. This result may be attributed to the following reasons. First, radical surgeries performed in right-sided and left-sided PCL are different and result in varied degrees of postoperative complications. A larger population-based study from the University HealthSystem Consortium Clinical Database revealed that right-sided colectomy led to fewer complications than left-sided colectomy for malignancy (26.8\% versus $28.3 \%, P<0.05$ ) [32]. Kwaan et al. [33] also reported that a high rate of superficial surgical site infection was found in left-sided colectomy. Therefore, we hypothesize that an increased complication rate would counteract the positive efficacy of surgical intervention in left-sided PCL. Second, the different surgical effect by tumor site is likely related to the biological characteristics of the tumor. The embryological midgut develops into the right-sided colon during development (including from the cecum to the proximal two-thirds of the transverse colon), and the embryological hindgut develops into the left-sided colon (including from the distal third of the transverse colon to the upper anal canal) [34]. The biological characteristics and gene variations may differ between right-sided and left-sided PCL, which may affect the therapeutic response to chemotherapy or targeted therapy. Ferreri et al. [35] investigated the role of surgical intervention in the therapy of gastric lymphoma by reviewing retrospective and prospective studies and suggested that nonsurgical treatments, such as chemotherapy, achieved equal or better outcomes than gastrectomy. Hence, considering the larger injury and high risk of permanent stoma caused by leftsided colorectal radical surgery, we suggest that surgeons should circumspectly recommend radical surgery for left-sided PCL. Combined chemotherapy with or without target therapy may be as effective as surgical intervention in these patients.

Radical resection has been the primary method for surgery of PCL, but the efficacy of this technique has not been proven in any clinical trials or retrospective studies. The present data demonstrated that approximately $29.4 \%$ of PCL patients underwent LE, which contradicts previous reports. Notably, univariate analysis revealed significantly prolonged survival in patients who underwent LE $(P<$ $0.001)$, but this survival benefit was lost in patients who received $\operatorname{RE}(P=0.177)$. We hypothesize that increased postoperative mortality counteracts the positive longterm effect of radical resection. However, the fact that patients who received LE were diagnosed at an earlier stage and were slightly younger should not be ignored. This survival difference was likely disturbed by selection bias, which arose from stage and age migration. Our failure to confirm this result in multivariate analysis and the unavoidable limitations in the current study prevent us from drawing the conclusion that patients who underwent LE exhibit improved survival. LE has the advantages of fewer operative injuries, faster recovery, cost savings, and avoidance of permanent stoma compared to RE. Therefore, a large-scale prospective clinical trial must be performed to reevaluate the practical role of local and radical surgery in PCL treatment.

This study presents several limitations. First, important clinical information, such as chemotherapy data, surgical details, and treatment-related complications, were not released in the SEER standard data. Therefore, several potential prognostic factors were not considered in the analysis. Second, intrinsic limitations exist in the SEER database because of variations in data reporting and coding systems, patient migration, and selection bias [36]. The absence of centralized meticulous histopathology reports or reviews is another inextricable limitation of the SEER program. NHL encompasses a heterogeneous group of histological presentations, and the consistency and accuracy of pathology reports provided by multiple participating institutions are difficult to ensure. Therefore, we cannot ignore the potential misclassification of the patients included in this study.

\section{CONCLUSIONS}

Using a large nationwide cancer database, this study revealed that age, tumor stage, and histological type maybe independent predictors of PCL prognosis. Surgical intervention was associated with survival. Surgical intervention did not improve survival in patients with an advanced tumor stage, left-sided lesion, or indolent 
PCL, but early tumor stage, right-sided lesion, or diffuse large B-cell histological type seems to be the clinical characteristics of optimal surgical candidates. However, a prospective study must be performed to confirm these findings. An ideal individualized therapy could maximize survival benefit in patients.

\section{MATERIALS AND METHODS}

\section{Data source}

The SEER program is supported by the National Cancer Institute and collects data on cancer incidence and survival from 18 participating population-based cancer registries. This program covers about $28 \%$ of the US population, which is approximately 86.4 million people, and updates information annually, including patient demographics, tumor characteristics, treatment and follow-up data [37]. The current study used the SEER database April 2014 release to identify all patients with PCL from 1973 to 2011. Information on patient demographics, tumor characteristics, surgery, radiation and survival data were extracted from this database. The site of the primary tumor was classified into right-sided colon (including cecum, appendix, right colon, hepatic flexure and transverse colon), left-sided colon (including splenic flexure, left colon and sigmoid colon) and rectum (overlapping lesions and rectum) in further survival study. Our analyses used the Ann Arbor staging from the SEER program as the staging criterion.

We partitioned surgical interventions into two types, local excision (LE) and radical excision (RE), to probe the relationship between surgery methods and survival outcomes. LE was defined as an intervention that resected or destroyed the primary mass locally, including damage surgery, partial resection, and palliative surgery [Site specific surgery (1973-1997) codes of 10-30,or Surgery of primary site (starting from 1998) codes of 10-32]. RE was defined as an intervention that resected the tumor radically, with a larger resection range than LE, including hemicolectomy, total colectomy, and proctocolectomy [Site specific surgery (1973-1997) codes of 40-50,70,or Surgery of primary site (starting from 1998) codes of4070].

\section{Inclusion and exclusion criteria}

There were 3 inclusion criteria in the current study: (1) Anatomic site of the primary tumor localized on the colon or the rectum (the International Classification of Disease for Oncology, Third Edition code, ICD-O-3: C180-189, C199 and C209); (2) Histological type limited to lymphoma (ICD-O-3 histology codes: 9590-9738); and (3) Malignant behavior (Behavior code ICD-O-3 code: 3 ).
Mantle cell lymphoma (ICD-O-3 histology codes: 9673), diffuse large B-cell lymphoma (9680), Burkitt lymphoma (9687), follicular lymphoma (9690-9698) and marginal zone B-cell lymphoma (9699) were included in this analysis because these types constitute the vast majority of cases. The current study used 3 exclusion criteria: (1) Patients without histological confirmation (Diagnostic Confirmation codes: 2, 4, 5, 6, 7, 8, 9); (2) Patients with death certificate only (Type of reporting death code: 7); and (3) Patients with unclear information regarding surgery. Patients with multiple primary tumors without active follow-up or explicit survival results were also excluded from the survival study to improve the accuracy of survival analyses. Figure 1 shows the detailed screening procedure.

\section{Statistical analysis}

Statistical analysis was performed using SPSS statistical software version 19.0 (SPSS Inc., IBM Corporation, Chicago, IL, USA) and R version 3.2.3 software (R Foundation for Statistical Computing, Vienna, Austria). Significant differences in patient demographics and tumor characteristics between the two groups were detected using the Pearson Chi-square test and the Wilcoxon rank sum test. We calculated the number of months from the date of diagnosis to the date of death to acquire OS. Univariate and multivariate models were established to evaluate correlations between various covariates and survival. The model-fitting methods were divided into three steps to ensure the quality of the regression analysis: variable selection, proportional hazards assumption verification and modeling, and goodness-of-fit assessment. Related references were consulted $[11,12,27]$ to compare clinical experiences, age at diagnosis, gender, race, stage, tumor location, histological type, surgery, radiation and year of diagnosis, which were included as relevant covariates in the univariate analysis. The Kaplan-Meier method was performed to calculate the median and 10-year OS, and log-rank statistics were used to detect survival differences between the various covariates. We performed the Cox proportional hazard model to estimate the adjusted HRs between survival and covariates. Statistically significant covariates identified in univariate analyses $(P<0.1)$ were included in crude multivariate models, and their respective interactions were tested. Forward elimination was used to remove covariates with $P>0.05$ until all the remaining variables had $P$ values $<0.05$ in at least one stratum. The required proportional hazards assumption was tested and satisfied. The goodness-of-fit of the Cox model was evaluated using the Harrell concordance index.

Patients with missing data were excluded from the univariate and multivariate analyses. Two-sided $P$-values $<0.05$ were considered statistically significant. All confidence intervals were set as 95\% CI. 


\section{ACKNOWLEDGMENTS}

We would like to thank all the staff in the National Cancer Institute and every member involved with the Surveillance, Epidemiology and End Results (SEER) Program.

\section{CONFLICTS OF INTEREST}

The authors made no disclosures.

\section{GRANT SUPPORT}

This work was partly supported by National Natural Science Foundation of China (NO.81272455, NO.81472664) and Zhejiang Provincial Natural Science Foundation of China (No. LY16H16011).

\section{REFERENCES}

1. Krol AD, le Cessie S, Snijder S, Kluin-Nelemans JC, Kluin PM and Noordijk EM. Primary extranodal nonHodgkin's lymphoma (NHL): the impact of alternative definitions tested in the Comprehensive Cancer Centre West population-based NHL registry. Annals of oncology. 2003; 14:131-139.

2. d'Amore F, Brincker H, Gronbaek K, Thorling K, Pedersen M, Jensen MK, Andersen E, Pedersen NT and Mortensen LS. Non-Hodgkin's lymphoma of the gastrointestinal tract: a population-based analysis of incidence, geographic distribution, clinicopathologic presentation features, and prognosis. Danish Lymphoma Study Group. Journal of clinical oncology. 1994; 12:1673-1684.

3. Zucca E, Roggero E, Bertoni F and Cavalli F. Primary extranodal non-Hodgkin's lymphomas. Part 1: Gastrointestinal, cutaneous and genitourinary lymphomas. Annals of oncology. 1997; 8:727-737.

4. Crump M, Gospodarowicz M and Shepherd FA. Lymphoma of the gastrointestinal tract. Seminars in oncology. 1999; 26:324-337.

5. Gurney KA, Cartwright RA and Gilman EA. Descriptive epidemiology of gastrointestinal non-Hodgkin's lymphoma in a population-based registry. British journal of cancer. 1999; 79:1929-1934.

6. Andrews CN, John Gill M, Urbanski SJ, Stewart D, Perini R and Beck P. Changing epidemiology and risk factors for gastrointestinal non-Hodgkin's lymphoma in a North American population: population-based study. The American journal of gastroenterology. 2008; 103:17621769.

7. Cheung MC, Housri N, Ogilvie MP, Sola JE and Koniaris LG. Surgery does not adversely affect survival in primary gastrointestinal lymphoma. Journal of surgical oncology. 2009; 100:59-64.
8. Fan CW, Changchien CR, Wang JY, Chen JS, Hsu KC, Tang R and Chiang JM. Primary colorectal lymphoma. Diseases of the colon and rectum. 2000; 43:1277-1282.

9. Gustafsson BI, Siddique L, Chan A, Dong M, Drozdov I, Kidd M and Modlin IM. Uncommon cancers of the small intestine, appendix and colon: an analysis of SEER 19732004, and current diagnosis and therapy. International journal of oncology. 2008; 33:1121-1131.

10. Tevlin R, Larkin JO, Hyland JM, O'Connell PR and Winter DC. Primary colorectal lymphoma - A single centre experience. The surgeon. 2015; 13:151-155.

11. Drolet S, Maclean AR, Stewart DA, Dixon E, Paolucci EO and Buie WD. Primary colorectal lymphomaclinical outcomes in a population-based series. Journal of gastrointestinal surgery. 2011; 15:1851-1857.

12. Kim YH, Lee JH, Yang SK, Kim TI, Kim JS, Kim HJ, Kim JI, Kim SW, Kim JO, Jung IK, Jung SA, Jung MK, Kim HS, et al. Primary colon lymphoma in Korea: a KASID (Korean Association for the Study of Intestinal Diseases) Study. Digestive diseases and sciences. 2005; 50:22432247.

13. Cai S, Cannizzo F, Jr., Bullard Dunn KM, Gibbs JF, Czuczman M and Rajput A. The role of surgical intervention in non-Hodgkin's lymphoma of the colon and rectum. American journal of surgery. 2007; 193:409-412; discussion 412 .

14. Dionigi G, Annoni M, Rovera F, Boni L, Villa F, Castano P, Bianchi V and Dionigi R. Primary colorectal lymphomas: review of the literature. Surgical oncology. 2007; 16 Suppl 1:S169-171.

15. Times M. Colorectal lymphoma. Clinics in colon and rectal surgery. 2011; 24:135-141.

16. Wong MT and Eu KW. Primary colorectal lymphomas. Colorectal disease. 2006; 8:586-591.

17. Wyatt SH, Fishman EK, Hruban RH and Siegelman SS. CT of primary colonic lymphoma. Clinical imaging. 1994; 18:131-141.

18. Aviles A, Neri N and Huerta-Guzman J. Large bowel lymphoma: an analysis of prognostic factors and therapy in 53 patients. Journal of surgical oncology. 2002; 80:111-115.

19. Bairey O, Ruchlemer R and Shpilberg O. Non-Hodgkin's lymphomas of the colon. The Israel Medical Association journal. 2006; 8:832-835.

20. Stanojevic GZ, Stojanovic MP, Stojanovic MM, Krivokapic Z, Jovanovic MM, Katic VV, Jeremic MM and Brankovic BR. Non-Hodgkin's lymphomas of the large bowel-clinical characteristics, prognostic factors and survival. Acta chirurgica Iugoslavica. 2008; 55:109-114.

21. Doolabh N, Anthony T, Simmang C, Bieligk S, Lee E, Huber P, Hughes R and Turnage R. Primary colonic lymphoma. Journal of surgical oncology. 2000; 74:257-262.

22. Musallam KM, Hatoum HA, Barada K, Taher AT, Salem ME, Malek EM and Shamseddine AI. Primary colorectal lymphoma. Medical oncology. 2010; 27:249-254. 
23. Busch E, Rodriguez-Bigas M, Mamounas E, Barcos M and Petrelli NJ. Primary colorectal non-Hodgkin's lymphoma. Annals of surgical oncology. 1994; 1:222-228.

24. Zighelboim J and Larson MV. Primary colonic lymphoma. Clinical presentation, histopathologic features, and outcome with combination chemotherapy. Journal of clinical gastroenterology. 1994; 18:291-297.

25. Li B, Shi YK, He XH, Zou SM, Zhou SY, Dong M, Yang JL, Liu P and Xue LY. Primary non-Hodgkin lymphomas in the small and large intestine: clinicopathological characteristics and management of 40 patients. International journal of hematology. 2008; 87:375-381.

26. Lai YL, Lin JK, Liang WY, Huang YC and Chang SC. Surgical resection combined with chemotherapy can help achieve better outcomes in patients with primary colonic lymphoma. Journal of surgical oncology. 2011; 104:265268.

27. Koch P, del Valle F, Berdel WE, Willich NA, Reers B, Hiddemann W, Grothaus-Pinke B, Reinartz G, Brockmann J, Temmesfeld A, Schmitz R, Rube C, Probst A, et al. Primary gastrointestinal non-Hodgkin's lymphoma: I. Anatomic and histologic distribution, clinical features, and survival data of 371 patients registered in the German Multicenter Study GIT NHL 01/92. Journal of clinical oncology. 2001; 19:3861-3873.

28. Pettengell R, Linch D and Haemato-Oncology Task Force of the British Committee for Standards in H. Position paper on the therapeutic use of rituximab in CD20-positive diffuse large B-cell non-Hodgkin's lymphoma. British journal of haematology. 2003; 121:44-48.

29. Pfreundschuh M, Trumper L, Osterborg A, Pettengell R, Trneny M, Imrie K, Ma D, Gill D, Walewski J, Zinzani PL, Stahel R, Kvaloy S, Shpilberg O, et al. CHOPlike chemotherapy plus rituximab versus CHOP-like chemotherapy alone in young patients with good-prognosis diffuse large-B-cell lymphoma: a randomised controlled trial by the MabThera International Trial (MInT) Group. The Lancet Oncology. 2006; 7:379-391.
30. Koniaris LG, Drugas G, Katzman PJ and Salloum R. Management of gastrointestinal lymphoma. Journal of the American College of Surgeons. 2003; 197:127-141.

31. Rackner VL, Thirlby RC and Ryan JA, Jr. Role of surgery in multimodality therapy for gastrointestinal lymphoma. American journal of surgery. 1991; 161:570-575.

32. Hinojosa MW, Konyalian VR, Murrell ZA, Varela JE, Stamos MJ and Nguyen NT. Outcomes of right and left colectomy at academic centers. The American surgeon. 2007; 73:945-948.

33. Kwaan MR, Al-Refaie WB, Parsons HM, Chow CJ, Rothenberger DA and Habermann EB. Are right-sided colectomy outcomes different from left-sided colectomy outcomes?: study of patients with colon cancer in the ACS NSQIP database. JAMA surgery. 2013; 148:504-510.

34. Meguid RA, Slidell MB, Wolfgang CL, Chang DC and Ahuja N. Is there a difference in survival between right- versus left-sided colon cancers? Annals of surgical oncology. 2008; 15:2388-2394.

35. Ferreri AJ and Montalban C. Primary diffuse large B-cell lymphoma of the stomach. Critical reviews in oncology/ hematology. 2007; 63:65-71.

36. Yu JB, Gross CP, Wilson LD and Smith BD. NCI SEER public-use data: applications and limitations in oncology research. Oncology. 2009; 23:288-295.

37. N. A. Howlader N, Krapcho M, Garshell J, Miller D, Altekruse SF, Kosary CL, Yu M, Ruhl J, Tatalovich Z,Mariotto A, Lewis DR, Chen HS, Feuer EJ, Cronin KA (eds), "SEER Cancer Statistics Review, 1975-2012, National Cancer Institute," Bethesda, MD, http://seer. cancer.gov/csr/1975_2012/, based on November 2014 SEER data submission, posted to the SEER web site, April 2015. 